\title{
A controversial insight into Southwest Pacific mid- Holocene seasonality: from corals to models
}

\author{
Claire E. Lazareth ${ }^{1}$, M.G. Bustamante Rosell', N. Duprey ${ }^{1}$, N. Pujol ${ }^{2}$, G. Cabioch ${ }^{1, \$}$, S. Caquineau ${ }^{1}$, T. Corrège ${ }^{2}$, F. Le Cornec ${ }^{1}$, C. Maes ${ }^{3}$, \\ M. MANDENG-Yogo ${ }^{1}$ AND B. TURCQ ${ }^{1}$ \\ 'IPSL/LOCEAN, UPMC/CNRS/IRD/MNHN, Institut de recherche pour le développement France Nord, Bondy, France; \\ claire.lazareth@locean-ipsl.upmc.fr \\ 2University of Bordeaux, Environnements et Paléoenvironnements Océaniques et Continentaux, Talence, France; ' 3 Laboratoire d'Etudes en Géo- \\ physique et Océanographie Spatiales, Institut de Recherche pour le Développement, Toulouse, France; \\ sTo Guy, in memoriam
} "Seasonal amplitude was higher in the Southwest Pacific during the mid-Holocene," say the corals. "It was not,"
reply the models. "More work is needed," agree the researchers...

In the Southwest (SW) Pacific, the seasonal changes in seawater surface characteristics, such as temperature (SST) and salinity (SSS), are governed mainly by the position and intensity of the South Pacific Convergence Zone (SPCZ) and by the occurrences of El Niño and La Niña events. The SPCZ is a southeast narrow cloudy belt that influences the wind and rain conditions from Papua New Guinea to French Polynesia (Trenberth 1976). During the austral summer, the SPCZ moves southwest whereas during the austral winter it moves north. Consequently, waters in the SW Pacific are generally warmer and less saline during the austral summer, and colder and saltier in winter. At the interannual time scale, the main changes in SST and SSS in the SW Pacific relate to EI Niño-Southern Oscillation (ENSO) dynamics, with a periodicity of ca. 2-7 years (Trenberth 1976). During an El Niño event, warm waters of the equatorial West Pacific (the Warm Pool) and connected precipitation migrate toward the central and eastern Pacific. Consequently, the SW Pacific SST decreases slightly while precipitation decreases strongly, leading to higher SSS (e.g. Delcroix 1998). The opposite occurs during La Niña events. Therefore, knowledge of past water characteristics at a seasonal resolution has the potential to provide information on the position and intensity of the SPCZ as well as on the occurrence of ENSO events. Mid-Holocene (6 ka BP) hydrographic proxy data from the SW Pacific are rare. However, this is a key period, characterized by a change in ENSO amplitude that is unfortunately not yet entirely understood.

\section{Corals and numerical models: tools to look back in time}

Past seasonal data on SST and SSS can be obtained from archives such as massive coral skeletons. The aragonitic skeleton of coral is secreted by polyps over several decades or centuries, at a rate of around

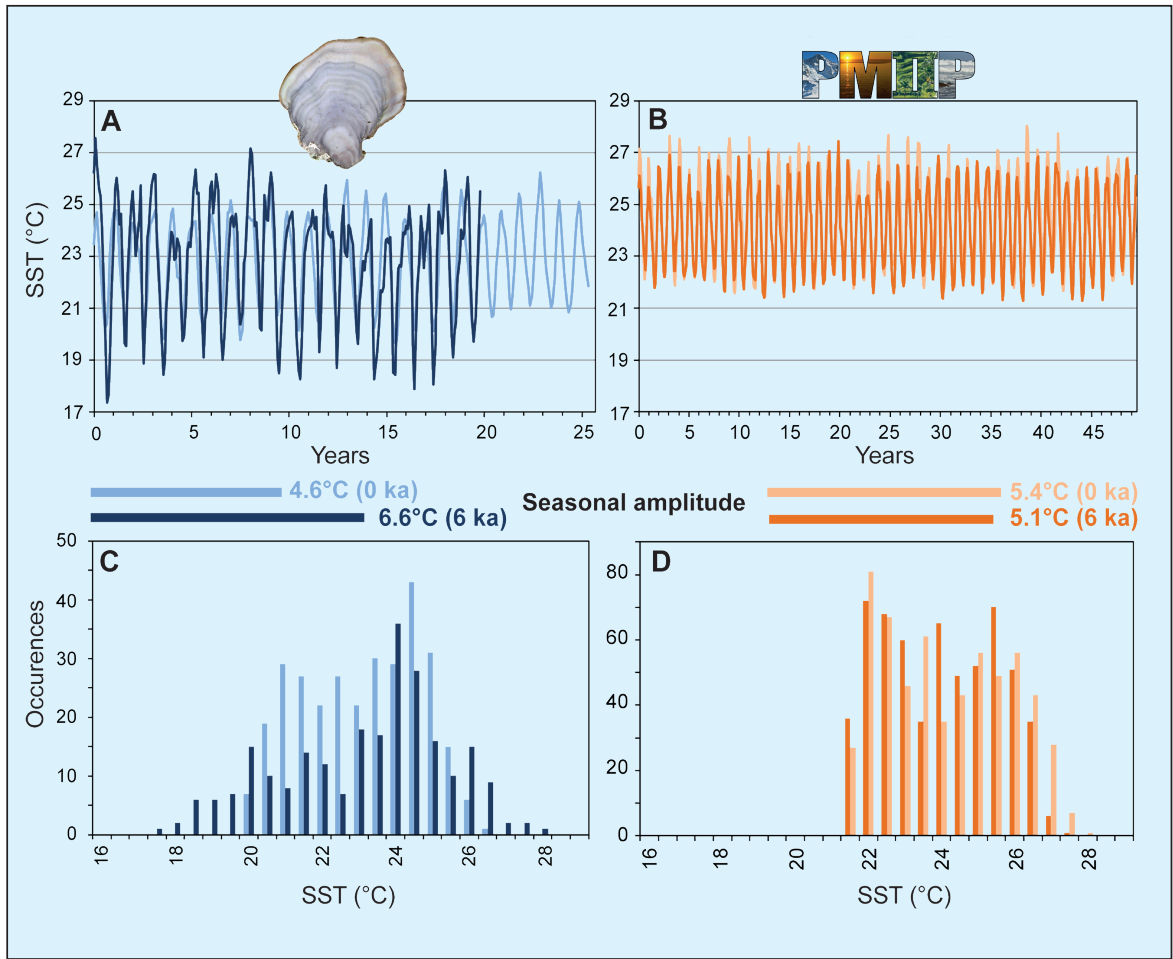

Figure 1: Comparison between coral (blue) and model run (orange) results in terms of sea surface temperature (SST; $\left.{ }^{\circ} \mathrm{C}\right)$ characteristics in the New Caledonia region for the present (light colors) and the mid-Holocene (dark colors) situations. A) Monthly coral time series from New Caledonia, at present (light blue, Stephans et al. 2004; Stephans et al. 2005) and from a coral fossil from the mid-Holocene (5.5 ka BP, dark blue; Lazareth et al. 2013). B) Monthly time series from the CCSM PMIP2-models for the New Caledonia region (160-164 $20-24^{\circ} \mathrm{S}$ ), at present (light orange) and at the mid-Holocene (6 ka BP; dark orange; Otto-Bliesner et al. 2006). C, D) Monthly SST histograms and calculated seasonal amplitude.

$1 \mathrm{~cm}$ year-1 for massive forms. The chemical composition of skeletal aragonite reflects the properties of the water in which the coral has lived. In tropical areas, studies focus on the massive Porites $s p$. corals. The Strontium/Calcium $(\mathrm{Sr} / \mathrm{Ca})$ ratio (Corrège 2006) is a robust proxy for SST in these corals. The stable oxygen isotopic ratio $\left(\delta^{18} \mathrm{O}\right)$ is used, combined with $\mathrm{Sr} / \mathrm{Ca}$, to reconstruct the isotopic composition of surface seawater $\left(\delta^{18} \mathrm{O}_{\mathrm{sw}}\right)$, which is in turn closely related to SSS (via the evaporation vs. precipitation budget).

Climate models, based on current knowledge of the various compartments of the Earth system, help understand modern climate variability and predict future changes. Climate models with external forcings different to current ones (e.g. different orbital forcings, ice sheets, greenhouse gas concentrations) can be used to simulate past climatic changes. Many model simulations exist for the mid-Holocene (e.g. 19 in the Paleoclimate Modelling Intercomparison Project [PMIP2] database; http://pmip2.Isce.ipsl. $\mathrm{fr} /$; Braconnot et al. 2007). Their main forcing is a millennial-scale change in the seasonality of insolation. For the SW Pacific region, the insolation for January to March was lower than at present while it was higher for August to October.

To gain an insight into SW Pacific mid-Holocene mean climate at seasonal resolution and hence into ENSO characteristics, we studied corals from New Caledonia and Vanuatu which have been dated to $5.5 \mathrm{ka} \mathrm{BP}$ and 6.7-6.5 ka 


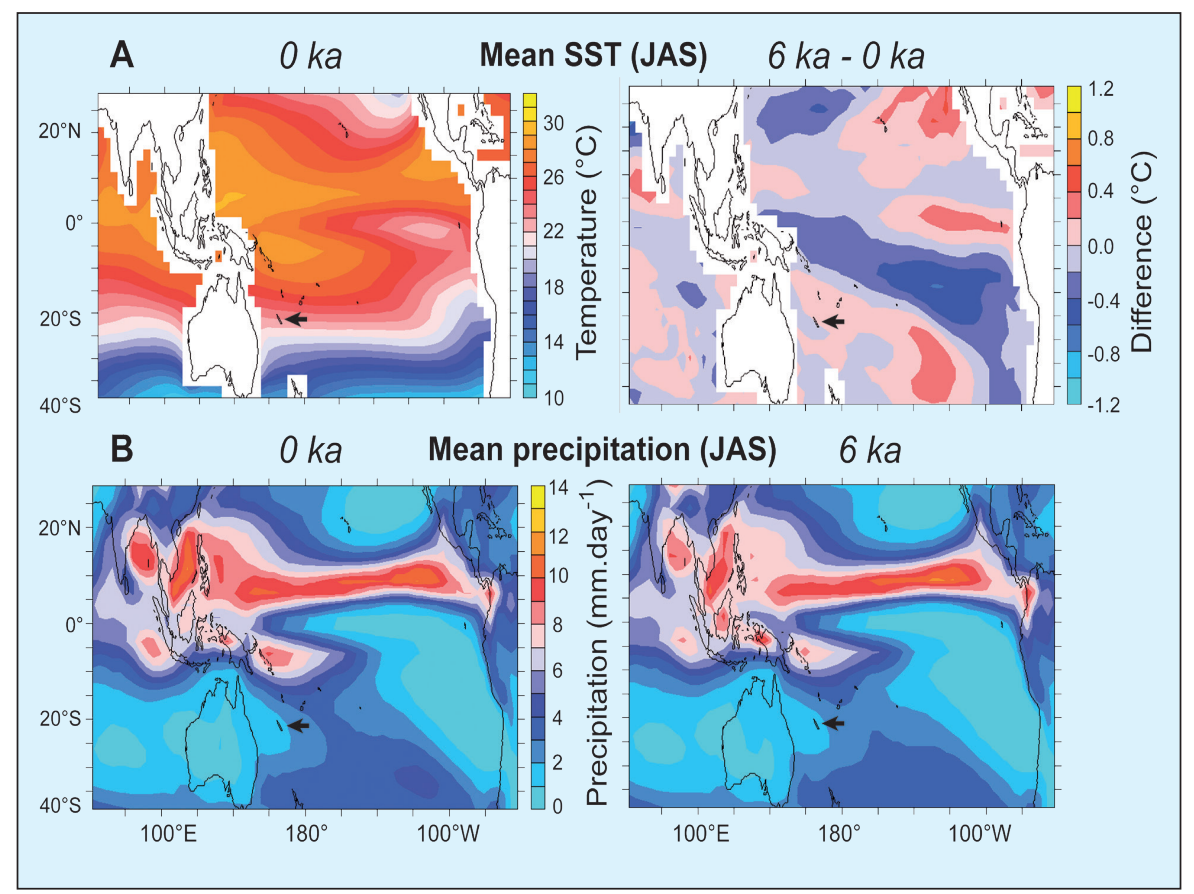

Figure 2: Multi-model mean maps for the winter season (July-August-September, JAS). Six PMIP2 simulations having similar resolution and reproducing correctly the mean seasonal cycle in the New Caledonia region have been used. The arrow points to New Caledonia. A) SST multi-model maps at $0 \mathrm{ka}$ (left) and difference (6 ka-0 ka; right). B) Multi-model mean precipitation field at $0 \mathrm{ka}$ (left) and $6 \mathrm{ka}$ (right). Modified from Lazareth et al. (2013).

BP respectively. $A \sim 1 \mathrm{~cm}$-thick slab, cut along the axis of maximum growth of the coral colonies, was X-rayed to reveal the annual growth bands. To ensure the skeleton was well preserved, pieces were collected and analyzed for their mineralogy using X-ray diffraction, and for their microstructure using scanning electronic microscopy. If the skeleton preservation was found to be satisfactory, the slab was continuously sampled at $1-\mathrm{mm}$ steps, providing on average one sample per month of coral growth. The samples were then dissolved and analyzed to determine their chemical composition. The New Caledonia coral was too short $(\sim 20$ years) to investigate ENSO dynamics and as the $\delta^{18} \mathrm{O}$ proved to be partly altered, only the SST reconstructed with Sr/Ca will be discussed here.

The 6 ka BP PMIP2 model simulations show a cooling of the tropical Pacific SST (Zheng et al. 2008) and a decrease in seasonal SST amplitude (south of $10^{\circ} \mathrm{S}$ and between $160-260^{\circ} \mathrm{E}$ for the South Pacific) related to the insolation change. The results obtained on the New Caledonia coral were compared with the six simulations for which monthly data were available and which correctly reproduced the current SST cycle in the New Caledonia region on four $2^{\circ}$ by $2^{\circ}$ grid points (164$\left.168^{\circ} \mathrm{E}, 20-24^{\circ} \mathrm{S}\right)$.

\section{The SPCZ at 6 ka BP: Where was it located?}

In the New Caledonia lagoon, the midHolocene SST seasonal amplitude as seen brought by the southward displacement of the SPCZ. The reconstructed high mid-Holocene SSS suggests that in the SW Pacific at 6.7-6.5 ka BP the SPCZ was located further north than nowadays (Duprey et al. 2012). At that time, ENSO variability was reduced by $20-30 \%$ compared to the modern ENSO. It remains uncertain, however, whether the reduced ENSO variability reflects a real trend in ENSO dynamics or if it resulted from a weaker coupling between the precipitation regime and the SPCZ.

\section{Are proxy data and models compatible for $6 \mathrm{ka}$ BP?}

While coral records suggest a reduced SPCZ influence in the SW Pacific, possibly from 6.7-6.5 to $5.5 \mathrm{ka}$ BP, the PMIP2 model maps of precipitation reveal only a small shift of the SPCZ towards the northeast and a decrease in associated precipitation during the winter months (Fig. 2b). These small changes, although in the right direction, are, however, not sufficient to simulate an increase in the SST seasonality in the SW Pacific region at 6 ka BP.

The modeled insolation-driven hemispheric change in seasonality is not reflected in the SW Pacific proxy data. This suggests the models have difficulty in reproducing mid-Holocene changes in coupled ocean-atmosphere circulation in this region. This could be due to known model biases in representing the current, and thus also the $6 \mathrm{ka} \mathrm{BP}, \mathrm{SPCZ}$, and to the models' large grid size to which the SPCZ seasonal displacement is sensitive. On the other hand, corals are shallow water organisms and the SST and SSS they record may not be valid for open oceans. Clearly, more data and new model runs are needed to understand the amplitude and geographical pattern of western Pacific mid-Holocene changes.

\section{Selected references}

Full reference list online under:

http://www.pages-igbp.org/products/newsletters/ref2013_2.pdf

er summer, leading to reduced seasonality (Fig. 1b).

For the Vanuatu corals, Sr/Ca and $\delta^{18} \mathrm{O}$ were measured as proxies for SST and SSS, respectively, and data from the longest colony were used to highlight ENSO characteristics during the early mid-Holocene. The precipitation regime in Vanuatu at 6.7-6.5 ka BP was different from the current one. Fossil corals indicate peaking SSS in summer (DJF) whereas low SSS would have been expected from the reduced summer insolation at that time. Indeed, summer today is accompanied by strong precipitation
Braconnot P et al. (2007) Climate of the Past 3: 261-277

Corrège T (2006) Palaeogeography Palaeodlimatology Palaeoecology 232: 408-428

Delcroix T (1998) Bulletin de I'Institut Français d'Etudes Andines 27: $475-483$

Duprey N et al. (2012) Paleoceanography 27, doi:10.1029/2012PA002350 Trenberth KE (1976) Quarterly Journal of the Royal Meteorological Society 102: 639-653 